\title{
Dividend multifactor process, long-run risk, and payout ratios
}

\author{
Claude Bergeron* \\ École des sciences de l'administration (ESA), \\ Université du Québec (TÉLUQ), \\ Québec, Québec, Canada \\ Email: claude.bergeron@teluq.ca \\ *Corresponding author

\section{Jean-Pierre Gueyie} \\ École des sciences de la gestion (ESG), \\ Université du Québec à Montréal (UQÀM), \\ Montréal, Québec, Canada \\ Email: gueyie.jean-pierre@uqam.ca

\section{Komlan Sedzro} \\ École des sciences de la gestion (ESG), \\ Université du Québec à Montréal (UQÀM), \\ Montréal, Québec, Canada \\ Email: sedzro.k@uqam.ca
}

\begin{abstract}
The purpose of this paper is to examine the theoretical relationship between the multidimensionality of risk and dividend policy, in an intertemporal context. After assuming that dividends are generated by a multifactor process, we use the fundamental framework of the consumption capital asset pricing model to explore the effect of longrun risk on dividend payout ratios (dividends divided by earnings). Our approach is similar to any multifactor model that, given the $N$ factor process, derives useful equilibrium conditions. Our main result shows that the dividend payout ratio is negatively related to $N$ sensitive coefficients, given by the long-run covariance between dividends and economic factors. This suggests that the multidimensionality of long-run consumption risk influences dividend policy. In brief, the model proposes that the target payout ratio can be determined with a simple and easy-to-apply formula that takes into account the long-run sensitivity of dividends to various economic factors.
\end{abstract}

Keywords: Multifactor model, Intertemporal model, CCAPM, Dividend policy, Payout ratio, Long-run risk

Reference to this paper should be made as follows: Bergeron, C., Gueyie, J.-P. and Sedzro, K. (201X) 'Dividend multifactor process, long-run risk, and payout ratios', American J. Finance and Accounting, Vol. XX No. X, pp. XX-XX. 
Biographical notes: Claude Bergeron, $\mathrm{PhD}$, is an Associate Professor of Finance at the University of Quebec (TÉLUQ), Canada. His research interests are in dividend policy, stock valuation, and intertemporal models. He has published research papers in international peer-reviewed journals such as Journal of Economics and Finance (Springer), Finance Research Letters (Elsevier), Finéco (2), and International Journal of Economics and Finance.

Jean-Pierre Gueyie, $\mathrm{PhD}$, is an Associate Professor at the School of Management, University of Quebec in Montreal. He received his Ph.D. from Laval University, Canada. He has published several papers in refereed scientific journals.

Komlan Sedzro, $\mathrm{PhD}$, is a Professor at the School of Management of University of Quebec in Montreal (ESG-UQAM). Professor Sedzro has a broad range of research interests encompassing such areas as governance and performance evaluation of financial and microcredit institutions, corporate finance, optimal portfolio allocation, alternative investments including hedge funds, real estate and commodity derivatives, and the application of operational research methods in finance. He has published numerous articles and given presentations at various international conferences on these topics.

\section{Introduction}

According to Ferson, Nallareddy and Xie (2013), the long-run risk model following Bansal and Yaron (2004) has been a phenomenal success. They argue that an important expending literature finds the model useful for the equity premium puzzle, size and book-to-market effects, momentum, risk premiums in bond markets, real exchange rate movements, and more. ${ }^{1}$

In fact, Bansal and Yaron maintain that consumption and dividend growth rates include a small long-run component that, in conjunction with Epstein and Zin's (1989) preferences, explains key asset market phenomena, and resolves the equity premium puzzle. Moreover, Bansal et al. (2005) show that cash flow betas, a measure of risk calculated by the long-run covariance between dividends and consumption, account for more than $60 \%$ of the cross-sectional variation in risk premia. Additionally, Hansen et al. (2008) reveal that growth-rate variations in consumption and cash flows have important consequences for asset valuation. For example, they indicate how valuation based measures of the duration of cash flows are linked to the long-run riskiness of the cash flows, and show that the cash flow growth of value portfolios has a positive correlation with consumption, over the long-run. In addition, Bansal et al. (2009) argue that the cointegrating relation between dividends and consumption is a key determinant of risk premia at all investment horizons. Likewise, Bansal and Kiku (2011) claim that the long-run equilibrium relation measured via a stochastic cointegration between aggregate consumption and dividends has significant implications for dividend growth rates and returns dynamics. Further, 
Bansal and Shaliastovich (2013) propose that inflation influences asset returns because inflation is exposed to the same real shocks that drive consumption and longrun risk. Furthermore, Bergeron (2013) develops a theoretical stock valuation model that considers the long-run sensitivity of dividends to various economic factors. In particular, the model reveals that a stock's long-run dividend growth is negatively related to its current dividend-price ratio and is linearly related to $N$ sensitivity coefficients, given by the long-run covariance between dividends and economic factors.

This paper extends the above mentioned studies by using the long-run concept of risk, as well as the multidimensionality of dividend sensitivity, to characterize the target dividend payout ratio of a firm.

As mentioned by DeFusco, Dunham and Geppert (2014), the question of whether dividend policy impacts firm value remains an important and highly debated question in finance. In their famous, and controversial paper, Miller and Modigliani (1961) demonstrated that under certain conditions the dividend policy followed by a firm does not affect is value. In a world without taxes, transaction costs, or other market imperfections, Miller and Modigliani proposed that there is no optimal dividend policy. However, in a world with market imperfections the possibility arises that dividends may affect value, and information asymmetries (between managers and investors) or agency costs are frequently proposed as possible explanations for optimal dividend policy. For instance, Battacharya (1979) suggests that the signalling benefits from paying dividends may be traded off against the tax disadvantages in order to achieve optimal payout policy. On the order hand, Rozeff (1982) suggests that cross-sectional regularities in corporate dividend policy may be explained by a trade-off between the costs of external capital and the benefit of reduced agency costs when the firm increases its dividend payments. In line with this view, Jensen (1986) argues that the main benefit of dividends is to give shareholders the means to reduce the free cash flows available for unproductive spending.

The literature also provides interesting observations on the link between dividends and risk. For example, several empirical observations have shown that the dividend payout ratio is lower for high-risk stocks. ${ }^{2}$ In the same manner, several studies report a negative relationship between the dividend yield and different measures of risk. ${ }^{3}$ Additionally, Jagannathan et al. (2000) find that firms that only pay dividends show lower earnings volatility than firms that only repurchase. Further, Grullon and Michaely (2002) stress that firms that pay dividends have a lower variability of return on assets than firms that do not pay dividends. Grullon et al. (2002) also confirms the notion that firms that increase dividends do so when they become more mature and less risky. Likewise, Brav et al. (2005) find that nearly $40 \%$ of managers believe that dividends make stocks less risky. Moreover, Carter (2008) develops a mathematical model that characterises the negative relationship between 
dividends and systematic risk. Furthermore, the empirical findings of Hussainey et al. (2011) suggest that, in the UK, there is a significant negative relationship between the payout ratio of a firm and the volatility of its stock price. In addition, Bergeron (2012) demonstrates that dividends are negatively related to the covariance between dividends and consumption. More recently, Rahgozar (2015) shows that dividendspaying stock prices are less volatile than non-dividends-paying stocks.

Nevertheless, none of these above-mentioned works examine the theoretical relationship between dividend policy and the multiple dimensions of long-run risk.

The purpose of this paper is to develop a theoritical model on the relationship between the target dividend payout ratio of a firm and the long-run sensitivity of dividends to various economic factors.

The development of the model implies the following steps. First, we suppose that stock dividend growth rates are generated by a number of economic factors (the dividend multifactor process). Second, we use the intertemporal framework of the consumption capital asset pricing model (CCAPM) of Rubinstein (1976), Lucas (1978) and Breeden (1979) to characterize the hypothetical economy. Third, we isolate the equilibrium expected dividend growth rate of a stock, and integrate the corresponding earnings into the relation. Fourth, we derive equilibrium relationships for one period and one factor, then for one period and several factors, and thereafter for many periods and several factors.

In this manner, we can show that the dividend payout ratio of a firm is negatively related to $N$ sensitivity coefficients, given by the long-run covariance between dividends and economic factors. This relation implies that the dividend payout ratio is nearly $100 \%$ when all sensitive coefficients approach zero; is identical to the aggregate payout ratio if the market dividend growth is the only factor and if the sensitive coefficient have a unit measure of sensitivity; and tends to zero when coefficients tends to infinity.

If we suppose that aggregate consumption represents the only factor that generates dividends, then it is easy to see that the only sensitive parameter is given by the long-run covariance between dividends and aggregate consumption. Thus, for this simple particular case, the sensitive coefficient is consistent with the definition of long-run risk (mentioned earlier).

The remainder paper is organized as follow. Section 2 describes the dividend multifactor process. Section 3 presents the intertemporal equilibrium framework. Section 4 derives the equilibrium relationships between dividend payout ratios and risks. Section 5 concludes. 


\section{The dividend multifactor process}

Following Bergeron (2013, p. 185), the primary assumption of our multifactor model is that stock dividend growth rates are generated by several economic factors. Given the available information in time $t$, we suppose that the dividend growth rate of stock $i$, between time $t$ and time $t+1, \tilde{g}_{i, t+1}$, is a linear function of $N$ factors.

More precisely, we assume that the dividend multifactor process can be written as follows: ${ }^{4}$

$$
\tilde{g}_{i, t+1}=a_{i t}+b_{1 i t} \widetilde{F}_{1, t+1}+b_{2 i t} \widetilde{F}_{2, t+1}+\ldots+b_{N i t} \widetilde{F}_{N, t+1}+\widetilde{\varepsilon}_{i, t+1},
$$

with

$$
E_{t}\left[\widetilde{\varepsilon}_{i, t+1}\right]=\operatorname{COV}_{t}\left[\tilde{\varepsilon}_{i, t+1}, \bullet\right]=0
$$

where $a_{i t}$ is the growth rate intercept for stock $i$ at time $t ; \widetilde{F}_{j, t+1}$, is the factor $j$ at time $t+1 ; b_{j i t}$, is the dividend growth rate sensitivity to factor $j$ for stock $i$ at time $t$; and $\widetilde{\varepsilon}_{i, t+1}$ is the usual random term associated to Equation (1A) for stock $i$ at time $t+1(j=$ $1,2,3, \ldots, N ; i=1,2,3, \ldots, M ; t=0,1,2, \ldots, \infty)$.

Notice that the second line of Equation (1A) simply assumes that the expected value of the usual random term is zero, as the covariance between this random term and any other variables.

To simplify the notation, we use the matrix algebra and rewrote the dividend multifactor process in this compact form:

$$
\tilde{g}_{i, t+1}=a_{i t}+\mathbf{b}_{i t}^{\prime} \tilde{\mathbf{F}}_{t+1}+\widetilde{\varepsilon}_{i, t+1}
$$

where $\widetilde{\mathbf{F}}_{t+1}$ is a column vector containing the elements $\widetilde{F}_{1, t+1}, \widetilde{F}_{2, t+1}, \ldots, \widetilde{F}_{N, t+1}$, while $\mathbf{b}_{i t}^{\prime}$ is a row vector containing the elements $b_{1 i t}, b_{2 i t}, \ldots, b_{N i t}$.

As noted by Bergeron, the process expressed by Equation (1) represents an approximation of the reality and the factors that we should integrate into the model are not determined by any economic theory, just as the standard multifactor model for returns. However, the rate of inflation, market dividend growth, industrial production growth and aggregate consumption growth were proposed as potential factors. In addition, as mentioned by the author, the usual linearity assumption adopted to express the multifactor process is not as restrictive as it might first appear. In fact, it 
is well known that a nonlinear model can be rewritten in a linear form (using the logarithm of a variable, for example).

\section{The intertemporal equilibrium framework}

Following Bergeron (2013, p. 187), the intertemporal equilibrium framework of our model considers a hypothetical economy, in which the representative investor maximizes the time-separable utility function:

$$
E_{t} \sum_{s=0}^{\infty} \delta^{s} U\left(\tilde{C}_{t+s}\right)
$$

where $\delta$ is the time discount factor $(0<\delta<1), U(\bullet)$ is an increasing concave and derivable function, and $\tilde{C}_{t+s}$ is the aggregate consumption at time $t+s$ $(s=0,1,2, \ldots, \infty)$.

The result of this problem leads us to the fundamental value of a long-live stock. ${ }^{5}$ That is to say:

$$
P_{i t}=E_{t} \sum_{s=1}^{\infty} \delta^{s} \frac{U^{\prime}\left(\tilde{C}_{t+s}\right)}{U^{\prime}\left(C_{t}\right)} \tilde{D}_{i, t+s}
$$

where $P_{i t}$ represents the price of stock $i$ at time $t$, and $\tilde{D}_{i, t+s}$ represents the dividends of stock $i$ at time $t+s(s=1,2, \ldots, \infty) .{ }^{6}$ Equation (3) shows that the price of a stock corresponds to the present value of all future cash flows (dividends), where the stochastic discount factor is equivalent to the intertemporal marginal rate of substitution between $t$ and $t+s\left(\tilde{M}_{t+s}\right)$, that is: $\tilde{M}_{t+s} \equiv \delta^{s} U^{\prime}\left(\tilde{C}_{t+s}\right) / U^{\prime}\left(C_{t}\right)$. Using this notation, the equilibrium price of a stock becomes:

$$
P_{i t}=E_{t} \sum_{s=1}^{\infty} \tilde{M}_{t+s} \tilde{D}_{i, t+s}
$$

Since the dividend of stock $i$ at time $t, D_{i t}$, is known with the current information, we can write:

$$
P_{i t}=D_{i t} E_{t} \sum_{s=1}^{\infty} \tilde{M}_{t+s} \tilde{D}_{i, t+s} / D_{i t}=D_{i t} E_{t}\left[\tilde{Y}_{i t}\right]
$$


where variable $\tilde{Y}_{i t}$ is defined in this manner: $\tilde{Y}_{i t} \equiv \sum_{s=1}^{\infty} \tilde{M}_{t+s} \tilde{D}_{i, t+s} / D_{i t}$.

If the variable $\tilde{Y}_{i t}$ is independent and identically distributed (i.i.d.), then we can simplify the relationship in this way (see, also, Bergeron, 2013):

$$
P_{i t}=D_{i t} E\left[\tilde{Y}_{i}\right]=D_{i t} \theta_{i}
$$

where $\theta_{i} \equiv E\left[\tilde{Y}_{i}\right]$. Given the available information at time $t$, we can see that:

$$
\tilde{P}_{i, t+1}=\tilde{D}_{i, t+1} \theta_{i}
$$

Recursively, Equation (4) can be expressed for one period (between $t$ and $t+1$ ), in the following manner:

$$
P_{i t}=E_{t}\left[\tilde{M}_{t+1}\left(\tilde{P}_{i, t+1}+\tilde{D}_{i, t+1}\right)\right]
$$

Substituting Equation (6) and Equation (7) in Equation (8) shows that:

$$
\theta_{i} D_{i t}=E_{t}\left[\tilde{M}_{t+1}\left(\theta_{i} \tilde{D}_{i, t+1}+\tilde{D}_{i, t+1}\right)\right]
$$

After simple manipulations (nothing that $\tilde{g}_{i, t+1} \equiv \tilde{D}_{i, t+1} / D_{i t}-1$ ) we can write:

$$
1=E_{t}\left[\tilde{M}_{t+1}\left(1+\tilde{g}_{i, t+1}\right)\left(1+\theta_{i}^{-1}\right)\right]
$$

Taking the expectation on each side of Equation (10A) allows us to release the index $t$ of the conditional operator, to shows:

$$
1=E\left[\tilde{M}_{t+1}\left(1+\tilde{g}_{i, t+1}\right)\left(1+\theta_{i}^{-1}\right)\right]
$$

Multiplying by $E\left[\tilde{M}_{t+1}\right]$ on each side of Equation (10B), indicates that:

$$
0=E\left[\tilde{M}_{t+1}\left(1+\tilde{g}_{i, t+1}\right)\left(1+\theta_{i}^{-1}\right)\right]-E\left[\tilde{M}_{t+1}\right] / E\left[\tilde{M}_{t+1}\right]
$$

Integrating the last element into the expectation operator and simplifying, gives:

$$
0=E\left[\tilde{M}_{t+1}\left\{\left(1+\tilde{g}_{i, t+1}\right)\left(1+\theta_{i}^{-1}\right)-1 / E\left[\tilde{M}_{t+1}\right]\right\}\right] .
$$


The definition of covariance implies that:

$$
\begin{aligned}
& \operatorname{COV}\left[\tilde{M}_{t+1},\left(1+\tilde{g}_{i, t+1}\right)\left(1+\theta_{i}^{-1}\right)-1 / E\left[\tilde{M}_{t+1}\right]\right]= \\
& -E\left[\tilde{M}_{t+1}\right] E\left[\left(1+\tilde{g}_{i, t+1}\right)\left(1+\theta_{i}^{-1}\right)-1 / E\left[\tilde{M}_{t+1}\right]\right]
\end{aligned}
$$

and covariance properties show that:

$$
\left(1+\theta_{i}^{-1}\right) \operatorname{COV}\left[\tilde{M}_{t+1}, 1+\tilde{g}_{i, t+1}\right]=1-\left(1+\theta_{i}^{-1}\right) E\left[\tilde{M}_{t+1}\right] E\left[1+\tilde{g}_{i, t+1}\right]
$$

Therefore, in equilibrium, the expected divided growth of any stock satisfied:

$$
E\left[1+\tilde{g}_{i, t+1}\right]=1 /\left(1+\theta_{i}^{-1}\right) E\left[\tilde{M}_{t+1}\right]-\operatorname{COV}\left[\tilde{M}_{t+1}, 1+\tilde{g}_{i, t+1}\right] / E\left[\tilde{M}_{t+1}\right]
$$

To facilitate the estimation of Equation (15), we refer, like Bansal and Kiku (2011), to the standard assumption of a constant relative risk aversion via the power utility function: $U\left(\widetilde{C}_{t+s}\right)=\tilde{C}_{t+s}^{1-\gamma} /(1-\gamma)$, where $\gamma(\gamma>0)$ is the coefficient of relative risk aversion. With this assumption, the marginal rate of substitution between $t$ and $t+1$ becomes: $\tilde{M}_{t+1}=\delta\left(1+\tilde{g}_{t+1}\right)^{-\gamma}$, where $\tilde{g}_{t+1}$ represents the consumption growth rate between time $t$ and $t+1\left(\tilde{g}_{t+1} \equiv \tilde{C}_{t+1} / C_{t}-1\right)$.

In the same way, Equation (15) becomes:

$$
E\left[1+\tilde{g}_{i, t+1}\right]=\frac{1 /\left(1+\theta_{i}^{-1}\right)}{\delta E\left[\left(1+\tilde{g}_{t+1}\right)^{-\gamma}\right]}-\frac{\operatorname{COV}\left[\left(1+\tilde{g}_{t+1}\right)^{-\gamma}, 1+\tilde{g}_{i, t+1}\right]}{E\left[\left(1+\tilde{g}_{t+1}\right)^{-\gamma}\right]} .
$$

In addition, to simplify equation (16), we suppose (as in Rubinstein 1976) that the dividend of stock $i$ and the aggregate consumption are bivariate normally distributed. Based on the lemma of $\operatorname{Stein}^{7}$, we can rewrite equation (16) in this form:

$$
E\left[1+\tilde{g}_{i, t+1}\right]=\frac{1 /\left(1+\theta_{i}^{-1}\right)}{\delta E\left[\left(1+\tilde{g}_{t+1}\right)^{-\gamma}\right]}+\frac{\gamma E\left[\left(1+\tilde{g}_{t+1}\right)^{-\gamma-1}\right]}{E\left[\left(1+\widetilde{g}_{t+1}\right)^{-\gamma}\right]} \operatorname{COV}\left[1+\tilde{g}_{t+1}, 1+\tilde{g}_{i, t+1}\right]
$$

or, to simplified the notation:

$$
E\left[1+\tilde{g}_{i, t+1}\right]=A_{i t}+B_{t} \operatorname{COV}\left[1+\tilde{g}_{t+1}, 1+\tilde{g}_{i, t+1}\right],
$$

where 


$$
\begin{aligned}
A_{i t} & \equiv\left(1+\theta_{i}^{-1}\right)^{-1} / \delta E\left[\left(1+\tilde{g}_{t+1}\right)^{-\gamma}\right]>0, \\
B_{t} & \equiv \gamma E\left[\left(1+\tilde{g}_{t+1}\right)^{-\gamma-1}\right] / E\left[\left(1+\tilde{g}_{t+1}\right)^{-\gamma}\right]>0 .
\end{aligned}
$$

Equation (17) represents a basic equilibrium condition expressed with dividends. In the following section, we will combine the dividend multifactor process proposed in section 2 to this equilibrium condition.

\section{Payout ratios, factors and risks}

This section demonstrates that the dividend policy followed by firms depends on the multiple dimensions of long-run risks. We begin by isolating the covariance term. We then integrate the expected earnings to express dividend policies with payout ratios. Afterward, we derive equilibrium conditions for one period and one factor, then for one period and several factors, and thereafter for many periods and several factors.

\subsection{One period and one factor}

Isolating the covariance term, yields:

$$
\left(E\left[1+\widetilde{g}_{i, t+1}\right]-A_{i t}\right) / B_{t}=\operatorname{COV}\left[1+\tilde{g}_{t+1}, 1+\tilde{g}_{i, t+1}\right]
$$

From the definition of covariance, we have:

$$
\left(E\left[1+\widetilde{g}_{i, t+1}\right]-A_{i t}\right) / B_{t}=E\left[\left(1+\widetilde{g}_{t+1}\right)\left(1+\widetilde{g}_{i, t+1}\right)\right]-E\left[1+\widetilde{g}_{t+1}\right] E\left[1+\widetilde{g}_{i, t+1}\right],
$$

or, after simple manipulations:

$$
E\left[1+\tilde{g}_{i, t+1}\right]\left(1 / B_{t}+E\left[1+\tilde{g}_{t+1}\right]\right)-A_{i t} / B_{t}=E\left[\left(1+\tilde{g}_{t+1}\right)\left(1+\tilde{g}_{i, t+1}\right)\right] .
$$

Multiplying by $D_{i t}$ on each side of Equation (20), gives, after simple manipulations:

$$
E\left[\tilde{D}_{i, t+1}\right]\left(1 / B_{t}+E\left[1+\tilde{g}_{t+1}\right]\right)-D_{i t} A_{i t} / B_{t}=E\left[\left(1+\tilde{g}_{t+1}\right) \tilde{D}_{i, t+1}\right]
$$

Dividing each side by the expected dividends of the stock, allows us to write:

$$
\begin{gathered}
{\left[E\left[\tilde{D}_{i, t+1}\right]\left(1 / B_{t}+E\left[1+\tilde{g}_{t+1}\right]\right)-D_{i t} A_{i t} / B_{t}\right] / E\left[\tilde{D}_{i, t+1}\right]=} \\
E\left[\left(1+\tilde{g}_{t+1}\right) \tilde{D}_{i, t+1}\right] / E\left[\tilde{D}_{i, t+1}\right]
\end{gathered}
$$


To express the dividend policy with earnings (dividends on earnings), we suppose, as Bakshi and Chen (2005) or Dong and Hirshleifer (2005), that dividends are related to net earnings according to:

$$
\tilde{D}_{i, t+1}=d_{i} \tilde{X}_{i, t+1}+\tilde{e}_{i, t+1}
$$

with

$$
E\left[\tilde{e}_{i, t+1}\right]=\operatorname{COV}\left[\tilde{e}_{i, t+1}, \bullet\right]=0
$$

where $\tilde{X}_{i, t+1}$ represents the earnings of stock $i$ at time $t+1 ; d_{i}$ is the dividend payout ratio of stock $i$; and $\tilde{e}_{i, t+1}$ is the random term associated to Equation (22) for stock $i$ at time $t+1$. From the last assumption, we can see that:

$$
E\left[\tilde{D}_{i, t+1}\right]=d_{i} E\left[\tilde{X}_{i, t+1}\right]
$$

Integrating Equation (24) into the dominator of Equation (23), on each side, allows us to write:

$$
\begin{gathered}
{\left[E\left[\tilde{D}_{i, t+1}\right]\left(1 / B_{t}+E\left[1+\tilde{g}_{t+1}\right]\right)-D_{i t} A_{i t} / B_{t}\right] / d_{i t} E\left[\tilde{X}_{i, t+1}\right]=} \\
E\left[\left(1+\tilde{g}_{t+1}\right) \tilde{D}_{i, t+1}\right] / d_{i t} E\left[\tilde{X}_{i, t+1}\right] .
\end{gathered}
$$

Equation (25) also indicates that:

$$
\begin{gathered}
{\left[E\left[\tilde{D}_{i, t+1}\right]\left(1 / B_{t}+E\left[1+\tilde{g}_{t+1}\right]\right)-D_{i t} A_{i t} / B_{t}\right] / E\left[\tilde{X}_{i, t+1}\right]=} \\
E\left[\left(1+\tilde{g}_{t+1}\right) \tilde{D}_{i, t+1}\right] / E\left[\tilde{X}_{i, t+1}\right] .
\end{gathered}
$$

Adding $E\left[1+\tilde{g}_{t+1}\right]$ to both sides of Equation (26), gives:

$$
\begin{gathered}
E\left[1+\tilde{g}_{t+1}\right]+\left[E\left[\tilde{D}_{i, t+1}\right]\left(1 / B_{t}+E\left[1+\tilde{g}_{t+1}\right]\right)-D_{i t} A_{i t} / B_{t}\right] / E\left[\tilde{X}_{i, t+1}\right]= \\
E\left[1+\tilde{g}_{t+1}\right]+E\left[\left(1+\tilde{g}_{t+1}\right) \tilde{D}_{i, t+1}\right] / E\left[\tilde{X}_{i, t+1}\right]
\end{gathered}
$$

or, to simplify the notation:

$$
E\left[1+\tilde{g}_{t+1}\right]+\alpha_{i t}=E\left[1+\tilde{g}_{t+1}\right]+E_{t}\left[\left(1+\tilde{g}_{t+1}\right) \tilde{D}_{i, t+1}\right] / E\left[\tilde{X}_{i, t+1}\right]
$$


where $\alpha_{i t} \equiv\left[E\left[\tilde{D}_{i, t+1}\right]\left(1 / B_{t}+E\left[1+\tilde{g}_{t+1}\right]\right)-D_{i t} A_{i t} / B_{t}\right] / E\left[\tilde{X}_{i, t+1}\right]$.

Using the basic proprieties of mathematical expectation and rearranging, yields:

$$
E\left[\left(1+\tilde{g}_{t+1}\right)\left(1-\tilde{D}_{i, t+1} / E\left[\tilde{X}_{i, t+1}\right]\right)\right]=E\left[\left(1+\tilde{g}_{t+1}\right)\right]-\alpha_{i t},
$$

or, after simple manipulations:

$$
E\left[\left(1+\tilde{g}_{t+1}\right) \tilde{Z}_{i, t+1}\right]=1,
$$

where $\tilde{Z}_{i, t+1} \equiv \frac{1-\tilde{D}_{i, t+1} / E\left[\tilde{X}_{i, t+1}\right]}{E\left[1+\tilde{g}_{t+1}\right]-\alpha_{i t}}$.

No correlation with consumption

If there is a security (or a portfolio) whose dividends are uncorrelated with aggregate consumption, then we can also write that:

$$
E\left[\left(1+\tilde{g}_{t+1}\right) \tilde{Z}_{u, t+1}\right]=1,
$$

where the index $u$ denotes the security which is uncorrelated (in dividends) with consumption. Thus, Equation (29) minus Equation (30) shows that:

$$
E\left[\left(1+\tilde{g}_{t+1}\right)\left(\tilde{Z}_{i, t+1}-\tilde{Z}_{u, t+1}\right)\right]=0 .
$$

The definition of mathematical covariance indicates that:

$$
\operatorname{COV}\left[1+\tilde{g}_{t+1}, \tilde{Z}_{i, t+1}-\tilde{Z}_{u, t+1}\right]=-E\left[1+\tilde{g}_{t+1}\right] E\left[\tilde{Z}_{i, t+1}-\tilde{Z}_{u, t+1}\right] .
$$

Rearranging, also indicates that:

$$
E\left[\tilde{Z}_{i, t+1}\right]=E\left[\tilde{Z}_{u, t+1}\right]-\frac{\operatorname{COV}\left[1+\tilde{g}_{t+1}, \tilde{Z}_{i, t+1}\right]}{E\left[1+\tilde{g}_{t+1}\right]} .
$$

From Equation (29), we can rewrite Equation (33) in this form:

$$
E\left[1-\tilde{D}_{i, t+1} / E\left[\tilde{X}_{i, t+1}\right]\right]=
$$




$$
E\left[\tilde{Z}_{u, t+1}\right]\left(E\left[1+\tilde{g}_{t+1}\right]-\alpha_{i t}\right)-\frac{\operatorname{COV}\left[1+\tilde{g}_{t+1}, 1-\tilde{D}_{i, t+1} / E\left[\tilde{X}_{i, t+1}\right]\right]}{E\left[1+\tilde{g}_{t+1}\right]},
$$

or, using the basic proprieties of covariance:

$$
\begin{gathered}
E\left[1-\tilde{D}_{i, t+1} / E\left[\tilde{X}_{i, t+1}\right]\right]= \\
E\left[\tilde{Z}_{u, t+1}\right]\left(E\left[1+\tilde{g}_{t+1}\right]-\alpha_{i t}\right)+\frac{\operatorname{COV}\left[1+\tilde{g}_{t+1}, \tilde{D}_{i, t+1} / E\left[\tilde{X}_{i, t+1}\right]\right]}{E\left[1+\tilde{g}_{t+1}\right]} .
\end{gathered}
$$

Integrating Equation (28) in Equation (35) indicates that:

$$
\begin{gathered}
E\left[1-\tilde{D}_{i, t+1} / E\left[\tilde{X}_{i, t+1}\right]\right]= \\
E\left[\tilde{Z}_{u, t+1}\right]\left(E\left[\left(1+\widetilde{g}_{t+1}\right)\left(1-\tilde{D}_{i, t+1} / E\left[\tilde{X}_{i, t+1}\right]\right)\right]\right) \\
+\frac{\operatorname{COV}\left[1+\widetilde{g}_{t+1}, \tilde{D}_{i, t+1} / E\left[\tilde{X}_{i, t+1}\right]\right]}{E\left[1+\widetilde{g}_{t+1}\right]}
\end{gathered}
$$

Using this compact notation $E\left[\tilde{X}_{i, t+1}\right] \equiv \bar{X}_{i, t+1}$, Equation (36A) becomes:

$$
\begin{gathered}
E\left[1-\widetilde{D}_{i, t+1} / \bar{X}_{i, t+1}\right]= \\
E\left[\tilde{Z}_{u, t+1}\right]\left(E\left[\left(1+\widetilde{g}_{t+1}\right)\left(1-\widetilde{D}_{i, t+1} / \bar{X}_{i, t+1}\right)\right]\right) \\
+\frac{\operatorname{COV}\left[1+\widetilde{g}_{t+1}, \tilde{D}_{i, t+1} / \bar{X}_{i, t+1}\right]}{E\left[1+\tilde{g}_{t+1}\right]} .
\end{gathered}
$$

Integrating the definition of covariance allows us to write:

$$
\begin{gathered}
E\left[1-\tilde{D}_{i, t+1} / \bar{X}_{i, t+1}\right]= \\
E\left[\tilde{Z}_{u, t+1}\right]\left(E\left[\left(1+\widetilde{g}_{t+1}\right] E\left[1-\widetilde{D}_{i, t+1} / \bar{X}_{i, t+1}\right]+\operatorname{COV}\left[1+\tilde{g}_{t+1}, 1-\widetilde{D}_{i, t+1} / \bar{X}_{i, t+1}\right]\right)\right. \\
+\frac{\operatorname{COV}\left[1+\tilde{g}_{t+1}, \tilde{D}_{i, t+1} / \bar{X}_{i, t+1}\right]}{E\left[1+\tilde{g}_{t+1}\right]}
\end{gathered}
$$

or, if we prefer: 


$$
\begin{gathered}
E\left[1-\tilde{D}_{i, t+1} / \bar{X}_{i, t+1}\right]= \\
E\left[\tilde{Z}_{u, t+1}\right]\left(E\left[1+\widetilde{g}_{t+1}\right] E\left[1-\tilde{D}_{i, t+1} / \bar{X}_{i, t+1}\right]-\operatorname{COV}\left[1+\widetilde{g}_{t+1}, \tilde{D}_{i, t+1} / \bar{X}_{i, t+1}\right]\right) \\
+\operatorname{COV}\left[1+\tilde{g}_{t+1}, \tilde{D}_{i, t+1} / \bar{X}_{i, t+1}\right] / E\left[1+\tilde{g}_{t+1}\right] .
\end{gathered}
$$

Developing, we can see that:

$$
\begin{gathered}
E\left[1-\tilde{D}_{i, t+1} / \bar{X}_{i, t+1}\right]= \\
E\left[1-\tilde{D}_{i, t+1} / \bar{X}_{i, t+1}\right] E\left[1+\tilde{g}_{t+1}\right] E\left[\tilde{Z}_{u, t+1}\right] \\
+\operatorname{COV}\left[1+\tilde{g}_{t+1}, \tilde{D}_{i, t+1} / \bar{X}_{i, t+1}\right]\left(1 / E\left[1+\tilde{g}_{t+1}\right]-E\left[\tilde{Z}_{u, t+1}\right]\right) .
\end{gathered}
$$

Rearranging, again, and isolating the covariance term, yields:

$$
\begin{gathered}
E\left[1-\tilde{D}_{i, t+1} / \bar{X}_{i, t+1}\right]= \\
\frac{1 / E\left[1+\tilde{g}_{t+1}\right]-E\left[\tilde{Z}_{u, t+1}\right]}{1-E\left[\tilde{Z}_{u, t+1}\right] E\left[1+\tilde{g}_{t+1}\right]} \operatorname{COV}\left[1+\tilde{g}_{t+1}, \tilde{D}_{i, t+1} / \bar{X}_{i, t+1}\right] .
\end{gathered}
$$

Multiplying each side by the expected earnings of the stock, $E\left[\tilde{X}_{i, t+1}\right]$, gives:

$$
\begin{gathered}
E\left[\tilde{X}_{i, t+1}\right]-E\left[\tilde{D}_{i, t+1}\right]= \\
\frac{1 / E\left[1+\tilde{g}_{t+1}\right]-E\left[\tilde{Z}_{u, t+1}\right]}{1-E\left[\tilde{Z}_{u, t+1}\right] E\left[1+\tilde{g}_{t+1}\right]} \operatorname{COV}\left[1+\tilde{g}_{t+1}, \tilde{D}_{i, t+1}\right] .
\end{gathered}
$$

Similarly, dividing each side by the expected dividends of the stock, $E\left[\widetilde{D}_{i, t+1}\right]$, yields:

$$
\begin{gathered}
E\left[\tilde{X}_{i, t+1}\right] / E\left[\tilde{D}_{i, t+1}\right]= \\
1+\frac{1 / E\left[1+\tilde{g}_{t+1}\right]-E\left[\tilde{Z}_{u, t+1}\right]}{1-E\left[\tilde{Z}_{u, t+1}\right] E\left[1+\tilde{g}_{t+1}\right]} \operatorname{COV}\left[1+\tilde{g}_{t+1}, \frac{\tilde{D}_{i, t+1}}{E\left[\widetilde{D}_{i, t+1}\right]}\right]
\end{gathered}
$$

or, after manipulations:

$$
E\left[\tilde{X}_{i, t+1}\right] / E\left[\tilde{D}_{i, t+1}\right]=
$$




$$
1+\frac{1 / E\left[1+\tilde{g}_{t+1}\right]-E\left[\tilde{Z}_{u, t+1}\right]}{1-E\left[\tilde{Z}_{u, t+1}\right] E\left[1+\tilde{g}_{t+1}\right]} \operatorname{COV}\left[1+\tilde{g}_{t+1}, \widetilde{G}_{i, t+1}\right],
$$

with, $\tilde{G}_{i, t+1} \equiv\left(1+\tilde{g}_{i, t+1}\right) / E\left[1+\tilde{g}_{i, t+1}\right]$. Multiplying each side by $E\left[1+\tilde{g}_{t+1}\right]$, gives:

$$
E\left[\tilde{X}_{i, t+1}\right] / E\left[\tilde{D}_{i, t+1}\right]=1+\operatorname{COV}\left[\tilde{G}_{t+1}, \tilde{G}_{i, t+1}\right],
$$

with, $\tilde{G}_{t+1} \equiv\left(1+\tilde{g}_{t+1}\right) / E\left[1+\tilde{g}_{t+1}\right]$.

Equation (44) represents an equilibrium condition for one period and one factor. It shows that the ratio of earnings to dividends (sometimes called the dividend cover ratio) is positively and linearly related to the covariance between aggregate consumption and asset's dividends.

\section{Market portfolio}

For the market portfolio, denoted by the index $m$, we can also write that:

$$
E\left[\tilde{X}_{m, t+1}\right] / E\left[\tilde{D}_{m, t+1}\right]=1+\operatorname{COV}\left[\tilde{G}_{t+1}, \tilde{G}_{m, t+1}\right]
$$

In this manner, Equation (44) and Equation (45) show that:

$$
\frac{E\left[\tilde{X}_{i, t+1}\right]}{E\left[\tilde{D}_{i, t+1}\right]}=1+\left[\frac{E\left[\tilde{X}_{m, t+1}\right]}{E\left[\tilde{D}_{m, t+1}\right]}-1\right] \frac{\operatorname{COV}\left[\tilde{G}_{t+1}, \tilde{G}_{i, t+1}\right]}{\operatorname{COV}\left[\tilde{G}_{t+1}, \tilde{G}_{m, t+1}\right]}
$$

If we postulate that the covariance between aggregate dividends and aggregate consumption is positive (for the canonical CCAPM, aggregate consumption equals aggregate dividends), and if we postulate that expected market earnings is naturally superior to the expected market dividends (see Table 1 in Foerster and Sapp, 2011), then we can see that the relationship expressed by Equation (46) is effectively positive. When the covariance between consumption and asset's dividends equals zero, the earnings-dividends ratio corresponds to one. When the covariance is superior to zero, the earnings-dividends ratio is superior to one. When it is the market portfolio, it's earnings-dividends ratio is, according to equation (46), identical to $E\left[\tilde{X}_{m, t+1}\right] / E\left[\tilde{D}_{m, t+1}\right]$. When the covariance tends to infinity, the earnings-dividends ratio also tends to infinity.

\subsection{One period and $N$ factors}

Using the previous variable definitions or notations, and the previous assumptions regarding the dividend multifactor process, we can also suppose that: 


$$
\widetilde{G}_{i, t+1}=\beta_{0 i t}+\beta_{1 i t} \widetilde{F}_{1, t+1}+\beta_{2 i t} \widetilde{F}_{2, t+1}+\ldots+\beta_{N i t} \widetilde{F}_{N, t+1}+\widetilde{\varepsilon}_{i, t+1}
$$

with

$$
E\left[\widetilde{\varepsilon}_{i, t+1}\right]=\operatorname{COV}\left[\widetilde{\varepsilon}_{i, t+1}, \bullet\right]=0,
$$

where $\beta_{0 i t}$ is the dividend growth intercept for stock $i$ at time $t$; and $\beta_{j i t}$, is the dividend growth sensitivity to factor $j$ for stock $i$ at time $t$. Note that if the covariance between $\widetilde{D}_{i, t+1}$ and $\tilde{F}_{j, t+1}$ is zero, then the corresponding covariance between $\tilde{G}_{i, t+1}$ and the same factor is also zero.

In addition, as previously seen in section 2, we can simplify the notation, and the algebraic manipulations, using the compact matrix algebra. That is to say:

$$
\widetilde{G}_{i, t+1}=\beta_{0 i t}+\boldsymbol{\beta}_{i t}^{\prime} \tilde{\mathbf{F}}_{t+1}+\widetilde{\varepsilon}_{i, t+1},
$$

where $\boldsymbol{\beta}_{i t}^{\prime} \equiv\left[\beta_{1 i t} \beta_{2 i t} \ldots \beta_{N i t}\right]$.

Integrating Equation (47B) in Equation (46), permits us to extend toward a multidimensional expression, as it shows below:

$$
\frac{E\left[\tilde{X}_{i, t+1}\right]}{E\left[\tilde{D}_{i, t+1}\right]}=1+\left[\frac{E\left[\tilde{X}_{m, t+1}\right]}{E\left[\tilde{D}_{m, t+1}\right]}-1\right] \frac{\operatorname{COV}\left[\tilde{G}_{t+1}, \beta_{0 i t}+\boldsymbol{\beta}_{i t}^{\prime} \tilde{\mathbf{F}}_{t+1}+\widetilde{\varepsilon}_{i, t+1}\right]}{\operatorname{COV}\left[\widetilde{G}_{t+1}, \widetilde{G}_{m, t+1}\right]}
$$

Using covariance proprieties, Equation (48) can be arranged as a clear multilinear function. That is:

$$
\frac{E\left[\tilde{X}_{i, t+1}\right]}{E\left[\tilde{D}_{i, t+1}\right]}=1+\lambda_{1 t} \beta_{1 i t}+\lambda_{2 t} \beta_{2 i t}+\ldots+\lambda_{N t} \beta_{N i t}
$$

where $\lambda_{j t} \equiv\left[\frac{E\left[\tilde{X}_{m, t+1}\right]}{E\left[\tilde{D}_{m, t+1}\right]}-1\right] \frac{\operatorname{COV}\left[\tilde{G}_{t+1}, \tilde{F}_{j, t+1}\right]}{\operatorname{COV}\left[\widetilde{G}_{t+1}, \widetilde{G}_{m, t+1}\right]}$, for every $j=1,2, \ldots, N$.

Equation (49) now represents an equilibrium condition, when dividends are generated by $N$ factors, on a single period. It shows that the earnings-dividends ratio of a firm is linearly related to $N$ sensitivity coefficients, given by the sensitivity of dividends to economic factors. 
More insight can be gained into the meaning of $\lambda_{1 t}, \lambda_{2 t}, \ldots$, and $\lambda_{N t}$ by using Equation (49). Examine a portfolio with a $\beta_{1 i t}$ of one $\left(\beta_{1 i t}=1\right)$ and a value of zero for every other sensitivity coefficients $\left(\beta_{2 i t}=\beta_{3 i t}=\ldots=\beta_{N i t}=0\right)$. In this case, we can see that $\lambda_{1 t}$ corresponds to:

$$
\lambda_{1 t}=\left[\frac{E\left[\tilde{X}_{1, t+1}\right]}{E\left[\widetilde{D}_{1, t+1}\right]}-1\right]
$$

where the index "1" indicates that it is a portfolio only subject to the variability of factor 1 , and having a unit measure of sensitivity.

In general, we thus can write that all stocks have earnings-dividends ratios described by the $N$-dimensional hyperplane expressed by Equation (49) with:

$$
\lambda_{j t}=\left[\frac{E\left[\tilde{X}_{j, t+1}\right]}{E\left[\tilde{D}_{j, t+1}\right]}-1\right], \text { for every } j=1,2, \ldots, N,
$$

where the index " $j "$ indicates that it is a portfolio only subject to the variability of factor $j$, and having a unit measure of sensitivity.

\subsection{Many periods and $N$ factors}

For many periods, summing from $t=0$ to $T$-1 shows that:

$$
\sum_{t=0}^{T-1} \frac{E\left[\tilde{X}_{i, t+1}\right]}{E\left[\tilde{D}_{i, t+1}\right]}=\sum_{t=0}^{T-1}\left(1+\lambda_{1 t} \beta_{1 i t}+\lambda_{2 t} \beta_{2 i t}+\ldots+\lambda_{N t} \beta_{N i t}\right)
$$

or, if we prefer, using the basic proprieties of the summation operator:

$$
\sum_{t=0}^{T-1} \frac{E\left[\tilde{X}_{i, t+1}\right]}{E\left[\widetilde{D}_{i, t+1}\right]}=T+\sum_{t=0}^{T-1} \lambda_{1 t} \beta_{1 i t}+\sum_{t=0}^{T-1} \lambda_{2 t} \beta_{2 i t}+\ldots+\sum_{t=0}^{T-1} \lambda_{N t} \beta_{N i t} .
$$

From the stationary assumption expressed by equation (23), we can write:

$$
T \frac{E\left[\tilde{X}_{i, t+1}\right]}{E\left[\widetilde{D}_{i, t+1}\right]}=T+\sum_{t=0}^{T-1} \lambda_{1 t} \beta_{1 i t}+\sum_{t=0}^{T-1} \lambda_{2 t} \beta_{2 i t}+\ldots+\sum_{t=0}^{T-1} \lambda_{N t} \beta_{N i t} .
$$

Multiplying by $\sum_{t=0}^{T-1} \lambda_{1 t}, \sum_{t=0}^{T-1} \lambda_{2 t}, \ldots$, and $\sum_{t=0}^{T-1} \lambda_{N t}$ on each side of equation (52), yields: 


$$
T \frac{E\left[\tilde{X}_{i, t+1}\right]}{E\left[\tilde{D}_{i, t+1}\right]}=T+\sum_{t=0}^{T-1} \lambda_{1 t} \sum_{t=0}^{T-1} w_{1 t} \beta_{1 i t}+\sum_{t=0}^{T-1} \lambda_{2 t} \sum_{t=0}^{T-1} w_{2 t} \beta_{2 i t}+\ldots+\sum_{t=0}^{T-1} \lambda_{N t} \sum_{t=0}^{T-1} w_{N t} \beta_{N i t},
$$

where $w_{j t} \equiv \lambda_{j t} / \sum_{t=0}^{T-1} \lambda_{j t}$, with $\sum_{t=0}^{T-1} w_{j t}=1$, for every $j=1,2, \ldots, N$

Thus, dividing by $T$ on both sides of Equation (53) indicates that:

$$
\frac{E\left[\tilde{X}_{i, t+1}\right]}{E\left[\tilde{D}_{i, t+1}\right]}=1+\lambda_{1} \bar{\beta}_{1 i}+\lambda_{2} \bar{\beta}_{2 i}+\ldots+\lambda_{N} \bar{\beta}_{N i}
$$

where $\lambda_{j} \equiv \sum_{t=0}^{T-1} \lambda_{j t} / T$, and $\bar{\beta}_{j i} \equiv \sum_{t=0}^{T-1} w_{j t} \beta_{j i t}$, for every $j=1,2, \ldots, N$.

Here, parameter $\lambda_{j}$ can be viewed as the arithmetic average of time values $\lambda_{j t}$, while coefficient $\bar{\beta}_{j i}$ can be viewed as the weighted average sensitive coefficient of time values $\beta_{j i t}$, for every $j=1,2, \ldots, N$. We assume that the parameter $\lambda_{j}$ is positive. ${ }^{8}$ Taking the inverse of both sides of equation (54) finally shows that;

$$
\bar{d}_{i}=\frac{1}{1+\lambda_{1} \bar{\beta}_{1 i}+\lambda_{2} \bar{\beta}_{2 i}+\ldots+\lambda_{N} \bar{\beta}_{N i}}
$$

where $\bar{d}_{i} \equiv E\left[\tilde{D}_{i, t+1}\right] / E\left[\tilde{X}_{i, t+1}\right]$ can be interpreted as the target dividend payout ratio for stock $i$ (over the long-run). Equation (55) represents our principal result. It reveals that the target dividend payout ratio of a firm is negatively related to $N$ sensitivity coefficients, given by the long-run sensitivity of dividends to economic factors. If all the sensitive coefficients equal zero, then all earnings are distributed. If all the sensitive coefficients tend to infinity, then all earnings are reinvested. In the center of these two extremes, we can find the optimal dividend policy of the firm. ${ }^{9}$ It is also interesting to note that the development presented up this point is similar to any multifactor model that, given the $N$ factor process, derives an useful equilibrium condition (see, for example, Merton, 1973; or The Arbitrage Pricing Theory, APT, of Ross, 1976). Notice that this result can be easily extending using the asset's earning growth (see appendix A).

\subsection{Particular case: A two dimension visual example}

The following argument leads us to expect a negative relationship between dividends and risk: if firms are risk averse and cautious, then those operating in a high level of uncertainty will pay lower dividends to have enough retained earnings for bad 
earnings years. With the present particular case, we illustrate this relationship, on two dimensions.

Indeed, if we suppose, just for visual simplicity, that aggregate consumption represents the only factor that generate dividends, then, from equation (47):

$$
\tilde{G}_{i, t+1}=\beta_{0 i t}+\beta_{C i t} \widetilde{G}_{t+1}+\widetilde{\varepsilon}_{i, t+1}
$$

and it is easy to demonstrate that; ${ }^{10}$

$$
\beta_{C i t}=\operatorname{COV}\left[\tilde{G}_{t+1}, \tilde{G}_{i, t+1}\right] / \sigma^{2}\left[\tilde{G}_{t+1}\right]
$$

We can call the coefficient $\beta_{\text {Cit }}$ The dividend-consumption beta of stock $i$ at time $t$.

Accordingly, a particular simple case of equation (55) can be expressed in the following manner:

$$
\bar{d}_{i}=\frac{1}{1+\lambda_{C} \bar{\beta}_{C i}}
$$

where $\lambda_{C} \equiv \sum_{t=0}^{T-1} \lambda_{C t} / T$ and $\bar{\beta}_{C i} \equiv \sum_{t=0}^{T-1} w_{C t} \beta_{C i t}$

with $\lambda_{C t} \equiv\left[\frac{E\left[\tilde{X}_{m, t+1}\right]}{E\left[\tilde{D}_{m, t+1}\right]}-1\right] \frac{\operatorname{COV}\left[\tilde{G}_{t+1}, \tilde{G}_{t+1}\right]}{\operatorname{COV}\left[\tilde{G}_{t+1}, \tilde{G}_{m, t+1}\right]}$ and $w_{C t} \equiv \lambda_{C t} / \sum_{t=0}^{T-1} \lambda_{C t}$.

The parameter $\lambda_{C t}$ can also be estimated by the following equality:

$$
\lambda_{C t}=\left[\frac{E\left[\tilde{X}_{C, t+1}\right]}{E\left[\tilde{D}_{C, t+1}\right]}-1\right]
$$

where the index " $C$ " indicates that it is a portfolio (or a stock) only subject to the variability of aggregate consumption growth, and having a unit measure of sensitivity. We can call the coefficient $\bar{\beta}_{C i}$ The long-run dividend-consumption beta of stock $i$, or more simply, The long-run beta of stock $i$.

For this particular case, therefore, the dividend payout ratio of a stock appears to be negatively related to the long-run covariance between dividends and consumption (as demonstrated by Equation 44). For instance, assuming we need to 
estimate the target dividend payout ratio for a risky firm that presents a long-run dividend beta of $1.50\left(\bar{\beta}_{C i}=1.5\right)$. From Table 1 in DeFusco, Dunham and Geppert (2014), we can propose that the average payout ratio for a large sample of firms is approximately $45 \%$, and we can assert that $\lambda_{C}=0.45^{-1}-1 .^{11}$ As a result, the target payout ratio for this firm should be approximately $35.29 \%$, since equation (58) shows that:

$$
0.3529=\frac{1}{1+\left(0.45^{-1}-1\right) 1.50}
$$

If the long-run beta is equal to one, then the payout would be equal to $45 \%$. If the long-run beta would be superior (inferior) to one, then the payout ratio would be inferior (superior) to $45 \%$. If the long-run beta is equal to zero, then the payout would be equal to $100 \%$. For this numerical example, thus, the relationship could be illustrated by a curve that approaches the horizontal axis asymptotically, as shown in figure 1 .

\section{[INSERT FIGURE 1 HERE]}

In brief, if we accept that the long-run covariance between dividends and consumption represents a measure of risk (as many authors propose ${ }^{12}$ ), and if we accept that dividends and risk are negatively related (as several studies suggest ${ }^{13}$ ), then the negative dividend-risk relationship could be illustrated, in a two dimensional case, by equation (58) and figure 1 .

On the other hand, if we believe that dividends are generated by more than one factor, then the dividend-risk relationship should be descripted by the multifactor model expressed by equation (55), of the previous section.

\section{Conclusion}

There are many empirical studies on dividend-risk relationships. The contribution of this paper is essentially theoretical.

In this paper, we examined the relationship between the multidimensionality of long-run risks and dividends. After assuming that dividends are generated by a multifactor process, we demonstrated that the payout ratio of a firm is negatively related to $N$ sensitivity coefficients, given by the long-run covariance between dividends and economic factors. Overall, our extension development suggests that the multidimensionality of long-run risk should be considered in choosing the level of 
dividend payments. In this sense, it leads to practical applications that may be useful in managerial finance, especially for decisions regarding dividend policy.

Our methodological approach was based on a very solid framework, namely the intertemporal CCAPM. ${ }^{14}$ However, we used several restrictive assumptions concerning the utility function (the time-separable utility assumption, for example). It could be suitable, for future development, to generalize the utility function, using, for instance, recursive modeling (as Strzalecki, 2013).

\section{Notes}

1 For more details on the usefulness of the long-run risk model, see, also, Beeler and Campbell (2012), or the review by Bansal (2007).

2 Concerning the negative relationship between dividend payout ratio and risk, see, for example, Beaver et al. (1970), Rozeff (1982), and Lapointe (1996).

3 Concerning the negative relationship between dividend yield and risk, see, for example, Pettit (1977), Eades (1982), and Baskin (1989).

4 In this document, the operators $E_{t}, V A R_{t}$, and $C O V_{t}$ refer respectively to mathematical expectations, variance, and covariance, where index $t$ implies that we consider the available information at time $t$. Furthermore, the tilde $(\sim)$ indicates a random variable.

5 See Rubinstein (1976) or Cochrane (2005), chapter 1.

6 The premium $\left(U^{\prime}\right)$ is a derivative of a function.

7 If $x$ and $y$ are bivariate normally distributed: $\operatorname{COV}(y, f(x))=E\left(f^{\prime}(x)\right) \operatorname{COV}(y, x)$. See Huang and Litzenberger (p. 101).

8 If we accept, implicitly, that expected earnings are supposed to be superior to expected dividends, then the dividend payout ratio must be between zero and one, the earnings-dividends ratio must be superior to one, and the parameter $\lambda_{j}$ must be positive.

9 From equation (55), it is easy to see that if the market dividend growth is the only factor and if the sensitive coefficient has an unit measure of sensitivity, then the target payout ratio is identical to the aggregate payout ratio.

10 If $x, y$ and e represent general variables, and if $y=a+b x+e$, where $\operatorname{COV}(x, e)=0$, then $\operatorname{COV}(x$, $y)=\operatorname{COV}(x, a+b x+e)=\operatorname{COV}(x, x) b$. Therefore: $b=\operatorname{COV}(x, y) / \sigma^{2}(x)$.

11 Recall that for the canonical CCAPM, aggregate dividend corresponds to aggregate consumption.

12 Concerning the concept of long-run risk, see, again, Bansal and Yaron (2004), Bansal et al. (2005), Hansen et al. (2008), Bansal et al. (2009), Bansal and Kiku (2011), Bansal and Shaliastovich (2013), or Bergeron (2013). 
13 Concerning the negative relationship between dividends and risk, see, again, Beaver et al. (1970), Rozeff (1982), Lapointe (1996), Pettit (1977), Eades (1982), Baskin (1989), Jagannathan et al. (2000), Grullon and Michaely (2002), Grullon et al. (2002), Brav et al. (2005), Carter (2008), Hussainey et al. (2011), or Bergeron (2012).

14 Campbell and Cochrane (2000) consider that the CCAPM represents one the major advances in financial economics. This point of view is also asserted by Cochrane (2005) and $\mathrm{Li}$ (2010).

\section{References}

Bakshi, G. and Chen, Z. (2005) 'Stock valuation in dynamic economies', Journal of Financial Markets, Vol. 8, pp. 111-151.

Bansal, R. (2007) 'Long-run risks and financial markets', working paper, Review, Federal Reserve Bank of St. Louis, Vol. 89 No. 4, pp. 283-300.

Bansal, R., Dittmar, R.F. and Lundblad, C. (2005) 'Consumption, dividends, and the cross-section of equity returns', The Journal of Finance, Vol. 60 No. 4, pp. 1639-1672.

Bansal, R., Dittmar, R.F. and Kiku, D. (2009) 'Cointegration and consumption risks in asset returns', Review of Financial Studies, Vol. 22 No. 3, pp. 1343-1375.

Bansal, R. and Kiku, D. (2011) 'Cointegration and long-run asset allocation', Journal of Business and Economic Statistics, Vol. 29 No. 1, pp. 161-173.

Bansal, R. and Shaliastovich, I. (2013) 'A long-run risks explanation of predictability puzzles in bond and currency markets', The Review of Financial Studies, Vol. 26 No. 1, pp. 1-33.

Bansal, R. and Yaron, A. (2004) 'Risks for the long run: A potential resolution of asset pricing puzzles', The Journal of Finance, Vol. 59 No. 4, pp. 1481-1509.

Baskin, J. (1989) 'Dividend policy and the volatility of common stocks', Journal of Portfolio Management, Vol. 15 No. 3, pp. 19-25.

Battacharya, S. (1979) 'Imperfect information, dividend policy, and "The bird in the hand" Fallacy', Bell Journal of Economics, Vol. 10 No. 1, pp. 259-270.

Beaver, W., Kettler, P. and Scholes, M. (1970), 'The association between market determined and accounting determined risk measures', Accounting Review, Vol. 45 No. 4, pp. 654-682.

Beeler, J. and Campbell, J. (2012) 'The long-run risks model and aggregate asset prices: an empirical assessment', Critical Finance Review, Vol. 1 No. 1, pp. 141-182.

Bergeron, C. (2012) 'Dividend policy and consumption risk', International Journal of Economics and Finance, Vol. 4 No. 8, pp. 1-11.

Bergeron, C. (2013) 'Dividend sensitivity to economic factors, stock valuation, and long-run risk', Finance Research Letters, Vol. 11 No. 3, pp. 184-195.

Brav, A., Graham, J.R., Harvey, C.R., and Michaely, R. (2005), 'Payout policy in the $21^{\text {st }}$ century', Journal of Financial Economics, Vol. 77 No. 3, pp. 483-527.

Breeden, D.T. (1979) 'An intertemporal asset pricing model with stochastic consumption and investment opportunities”, Journal of Financial Economics, Vol. 7 No. 3, pp. 265-296.

Campbell, J.Y., and Cochrane, J.H. (2000) 'Explaining the poor performance of consumption-based asset pricing models', The Journal of Finance, Vol. 55 No. 6, pp. 2863-2878. 
Carter, M.S. (2008) 'The relationship between dividend payouts and systematic risk: a mathematical approach', Academy of Accounting and Financial Studies Journal, Vol. 12 No. 2.

Cochrane, J.H. (2005) Asset Pricing. Princeton University Press, Princeton N.J.

DeFusco, R.A., Dunham, L.M. and Geppert, J. (2014) 'An empirical analysis of the dynamic relation among investment, earnings and dividends', Managerial Finance, Vol. 40 No. 2, pp. 118-136.

Dong, M. and Hirshleifer, D. (2005) 'A generalized earnings-based stock valuation model', The Manchester School, Vol. 73, pp. 1-31.

Eades, K.M. (1982) 'Empirical Evidence on dividends as a signal of firm value', Journal of Financial and Quantitative Analysis, Vol. 17 No. 4, pp. 471-500.

Epstein, L. and Zin, S. (1989) 'Substitution, risk aversion and the temporal behavior of consumption and asset returns: A theoretical framework', Econometrica, Vol. 57 No. 4, pp. 937-969.

Ferson, W., Nallareddy, S. and Xie, B. (2013) 'The "out-of-sample" performance of long-run risk models', Journal of Financial Economics, Vol. 107 No. 3, pp. 537-556.

Foerster, S.R. and Sapp, S.G. (2011) 'Back to fundamentals: The role of expected cash flows in equity valuation', The North American Journal of Economics and Finance, Vol. 22 No. 3, pp. 320-343.

Grullon, G., and Michaely R. (2002) 'Dividends, share repurchases, and the substitution hypothesis?', The Journal of Finance, Vol. 57 No. 4, pp. 1649-1684.

Grullon, G., Michaely R. and Swaminathan, B. (2002) 'Are dividend changes a sign of maturity?', Journal of Business, Vol. 75 No. 3, pp. 387-424.

Hansen, L.P., Heaton, J.C. and Li, N. (2008) 'Consumption strikes back?: Measuring long-run risk', Journal of Political Economy, Vol. 116 No. 2, pp. 260-302.

Huang, C. and Litzenberger, R.H. (1988) Foundations for Financial Economics. Elsevier Science Publishing, New York, New York.

Hussainey, K., Mgbame, C.O. and Chijoke-Mgbame, A.M. (2011) 'Dividend policy and share price volatility: UK evidence', The Journal of Risk Finance, Vol. 12 No. 1, pp. 57-68.

Jagannathan, M., Stephens, C.P., and Weisbach M.S. (2000) 'Financial flexibility and the choice between dividends and stock repurchases", Journal of Financial Economics, Vol. 57 No. 3, pp. 355-384.

Jensen, M.C. (1986) 'Agency costs of free cash flow, corporate finance and take overs', American Economic Review, Vol. 76 No. 2, pp. 323-329.

Lapointe, M.-A. (1996) 'Signalisation via dividende et variabilité du flux monétaire', Finéco, Vol. 6 No. 2, pp. 55-70.

Li, B. (2010) 'Consumption and stock returns in Australia: A revisit', International Research Journal of Finance and Economics, Vol. 50 No. 1, pp. 26-44.

Lucas, R.E. (1978) 'Asset prices in an exchange economy', Econometrica, Vol. 46 No.6, pp. 14291445.

Merton, R.C. (1973) 'An intertemporal capital asset pricing model', Econometrica, Vol. 41 No. 5, pp. 867-887.

Miller, M.H., and Modigliani, F. (1961) 'Dividend policy, growth, and the valuation of shares', Journal of Business, Vol. 34 No. 2, pp. 411-433.

Pettit, R.R. (1977) 'Taxes, Transactions Costs and the clientele effect of dividends', Journal of Financial Economics, Vol. 5 No. 3, pp. 419-436. 
Rahgozar, R. (2015) 'The relationship between dividend- and non-dividend-paying stock prices when considering financial distress', American Journal of Finance and Accounting, Vol. 4 No. 1, pp. 19-27.

Ross, S. (1976) 'The arbitrage theory of capital asset pricing', Journal of Economic Theory, Vol. 13 No. 3, pp. 341-360.

Rozeff, M.S. (1982) 'Growth, beta and agency costs as determinants of dividend payout ratios', Journal of Financial Research, Vol. 5 No. 3, pp. 249-259.

Rubinstein, M. (1976) 'The valuation of uncertain income streams and the pricing of options', The Bell Journal of Economics, Vol. 7 No. 2, pp. 407-425.

Strzalecki, T. (2013) 'Temporal resolution of uncertainty and recursive models of ambiguity aversion', Econometrica, Vol. 81 No. 3, pp. 1039-1074.

\section{Appendix A}

Appendix A shows that our principal result (Equation 55) can be easily extending using earning growth rates. Indeed, Equation (23) in Equation (46) indicates that:

$$
\frac{E\left[\tilde{X}_{i, t+1}\right]}{E\left[\widetilde{D}_{i, t+1}\right]}=1+\left[\frac{E\left[\tilde{X}_{m, t+1}\right]}{E\left[\tilde{D}_{m, t+1}\right]}-1\right] \frac{\operatorname{COV}\left[\tilde{G}_{t+1}, \tilde{D}_{i, t+1} / E\left[\tilde{D}_{i, t+1}\right]\right]}{\operatorname{COV}\left[\widetilde{G}_{t+1}, \widetilde{D}_{m, t+1} / E\left[\widetilde{D}_{m, t+1}\right]\right]},
$$

is equivalent to:

$$
\frac{E\left[\tilde{X}_{i, t+1}\right]}{E\left[\tilde{D}_{i, t+1}\right]}=1+\left[\frac{E\left[\tilde{X}_{m, t+1}\right]}{E\left[\tilde{D}_{m, t+1}\right]}-1\right] \frac{\operatorname{COV}\left[\tilde{G}_{t+1}, \frac{d_{i} \tilde{X}_{i, t+1}+\tilde{e}_{i, t+1}}{d_{i} E\left[\tilde{X}_{i, t+1}\right]}\right]}{\operatorname{COV}\left[\tilde{G}_{t+1}, \frac{d_{m} \tilde{X}_{m, t+1}+\tilde{e}_{m, t+1}}{d_{m} E\left[\tilde{X}_{m, t+1}\right]}\right]},
$$

or:

$$
\frac{E\left[\tilde{X}_{i, t+1}\right]}{E\left[\tilde{D}_{i, t+1}\right]}=1+\left[\frac{E\left[\tilde{X}_{m, t+1}\right]}{E\left[\tilde{D}_{m, t+1}\right]}-1\right] \frac{\operatorname{COV}\left[\tilde{G}_{t+1}, \tilde{X}_{i, t+1} / E\left[\tilde{X}_{i, t+1}\right]\right]}{\operatorname{COV}\left[\widetilde{G}_{t+1}, \tilde{X}_{m, t+1} / E\left[\tilde{X}_{m, t+1}\right]\right.},
$$

or if we prefer:

$$
\frac{E\left[\tilde{X}_{i, t+1}\right]}{E\left[\tilde{D}_{i, t+1}\right]}=1+\left[\frac{E\left[\tilde{X}_{m, t+1}\right]}{E\left[\tilde{D}_{m, t+1}\right]}-1\right] \frac{\operatorname{COV}\left[\tilde{G}_{t+1}, \tilde{G}_{i, t+1}^{E}\right]}{\operatorname{COV}\left[\widetilde{G}_{t+1}, \tilde{G}_{m, t+1}^{E}\right]},
$$


with, $\tilde{G}_{i, t+1}^{E} \equiv\left(1+\tilde{g}_{i, t+1}^{E}\right) / E\left[1+\tilde{g}_{i, t+1}^{E}\right]$ and $\tilde{g}_{i, t+1}^{E} \equiv \tilde{X}_{i, t+1} / X_{i t}-1$, where $X_{i t}$ represents the earnings of stock $i$ at time $t$, and where the index $m$ indicates the market portfolio.

In this manner, Equation (A4), with earnings, is equivalent to Equation (46), with dividends. In addition, if we integrate Equation (23) in Equation (47), we can write:

$$
\frac{d_{i} \tilde{X}_{i, t+1}+\tilde{e}_{i, t+1}}{d_{i} E\left[\tilde{X}_{i, t+1}\right]}=\beta_{0 i t}+\beta_{1 i t} \tilde{F}_{1, t+1}+\beta_{2 i t} \tilde{F}_{2, t+1}+\ldots+\beta_{N i t} \tilde{F}_{N, t+1}+\widetilde{\varepsilon}_{i, t+1}
$$

or

$$
\tilde{G}_{i, t+1}^{E}=\beta_{0 i t}+\beta_{1 i t} \tilde{F}_{1, t+1}+\beta_{2 i t} \tilde{F}_{2, t+1}+\ldots+\beta_{N i t} \tilde{F}_{N, t+1}+\widetilde{\varepsilon}_{i, t+1}^{*}
$$

where $\widetilde{\varepsilon}_{i, t+1}^{*} \equiv \widetilde{\varepsilon}_{i, t+1}-\tilde{e}_{i, t+1} / d_{i} E\left[\tilde{X}_{i, t+1}\right]$, with $E\left[\tilde{\varepsilon}_{i, t+1}^{*}\right]=\operatorname{COV}\left[\tilde{\varepsilon}_{i, t+1}^{*}, \bullet\right]=0$.

Therefore, if we restart each step between Equation (47) and Equation (54), we finally find the same result (with earnings) as the one expressed by Equation (55). 


\section{Figure 1.}

The relationship between payout ratio and long-run beta, in a two dimensional special case.

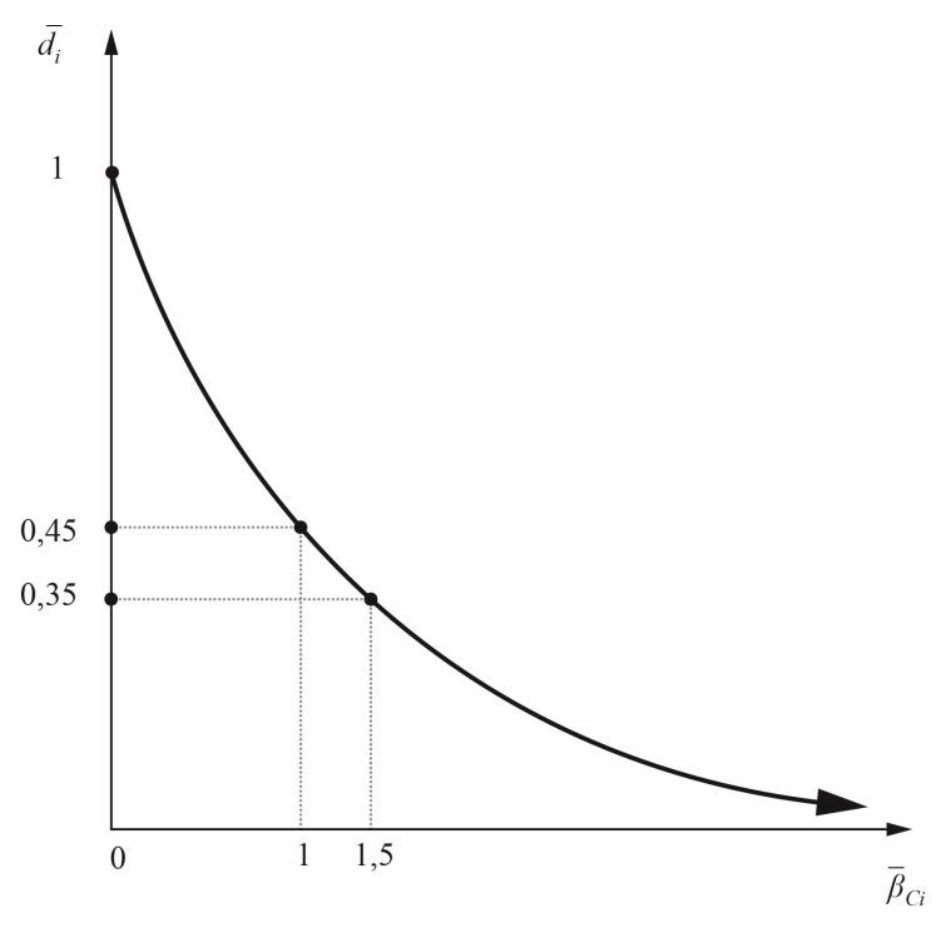

